\title{
INFLUENCE OF DOSE AND MOLECULAR WEIGHT ON FOLIAR MASS UPTAKE OF SURFACTANT
}

\author{
C.M. NIELSEN, K.D. STEELE, W.A. FORSTER and J.A. ZABKIEWICZ \\ Plant Protection Chemistry ${ }_{N Z}, P O$ Box 6282, Rotorua, New Zealand \\ Corresponding author: alison.forster@ppcnz.co.nz
}

\begin{abstract}
Foliar uptake of model xenobiotics and active ingredients on a unit area basis can be related to the initial dose of compound applied per unit area. Current concepts propose that ideally surfactants and active ingredients co-penetrate into plants. Other evidence has shown that this is not always the case, with pesticides and surfactants influencing each other's behaviour. Hence it is relevant to determine whether surfactants follow a similar mass uptake relationship. This study determined the uptake of five surfactants differing in structure and molecular weight (290-1350) into two plant species (fathen and wheat). The results showed that surfactants follow the same mass uptake relationship found previously for model compounds and active ingredients, i.e. the initial dose $\left(\mathrm{nmol} / \mathrm{mm}^{2}\right)$ of surfactant applied to plant foliage is a strong, positive determinant of uptake per unit area. However, at the constant concentration (\%) studied, surfactant molecular weight also played a role in uptake.

Keywords: cuticular uptake, mechanism, initial dose, models, surfactants.
\end{abstract}

\section{INTRODUCTION}

It has been clearly established (Forster et al. 2004) that foliar uptake of model xenobiotics on a unit area basis $\left(\mathrm{nmol} / \mathrm{mm}^{2}\right)$ can be related to the initial dose (ID) of compound applied per unit area, by an equation of the form: Uptake $=\mathrm{a}[\mathrm{ID}]^{\mathrm{b}}$ at time $t=24 \mathrm{~h}$, where $\mathrm{a}$ and $\mathrm{b}$ are constants specific to each compound. This relationship has been shown to apply in the case of representative water soluble, suspension concentrate (SC) and emulsified concentrate (EC) pesticide formulations (W.A. Forster, unpubl. data). Since pesticide uptake is known to be influenced by surfactants (Stock \& Holloway 1993) and as optimal uptake is thought to occur when there is co-penetration, it is relevant to determine whether these surfactants also follow the same mass uptake relationship.

\section{MATERIALS AND METHODS}

Fathen (Chenopodium album; sourced from Valley Seed Service, Fresno, CA) and wheat (Triticum aestivum; sourced from Wrightson, New Zealand) plants were grown from seed in individual pots containing Bloom potting mix (Yates Ltd). Plants were raised under controlled environment conditions (fathen: $23^{\circ} \mathrm{C} / 15^{\circ} \mathrm{C}$ day/night temperature, $14 \mathrm{~h}$ photoperiod, $70 \% \mathrm{RH}$ and ca $400 \mu \mathrm{mol} / \mathrm{m}^{2} / \mathrm{s}$; wheat: as for fathen but with $20^{\circ} \mathrm{C} / 15^{\circ} \mathrm{C}$ day/night temperature and a $12 \mathrm{~h}$ photoperiod). Fathen plants were used 4 weeks after sowing and wheat plants were used when they reached the 4-5 leaf growth stage (ca 25 days after sowing).

The solution application methods were similar to those described fully elsewhere (Forster et al. 2004a) but can be summarised as follows. Droplets (16 per leaf except for ON 30 which had 7 per leaf applied to prevent droplets merging) of five surfactants (Table 1) were applied to the upper leaf surfaces of fathen and wheat. After $24 \mathrm{~h}$ the treated leaves were excised, washed $(2 \times 4 \mathrm{ml} \mathrm{50 \%}$ methanol) to recover unabsorbed surfactant (all $>95 \%$ recovery on droplet dry-down) and the washings analysed by high performance liquid chromatography (HPLC). 
TABLE 1: Surfactants used in the experiment (all at $0.5 \% \mathrm{w} / \mathrm{v} ; 5 \mathrm{~g} / \mathrm{litre}$ ), along with their structure, molecular weight and molar concentration.

\begin{tabular}{llcc}
\hline Surfactant Structure & Molecular weight & $\begin{array}{c}\text { Molar concentration } \\
\text { (mmol/litre) }\end{array}$ \\
\hline ON 30 & alkyl EO ${ }^{1}$ polymer & 290 & 17.24 \\
ON 80 & alkyl EO polymer & 510 & 9.80 \\
At 11 & alkyl EO polymer & 740 & 6.76 \\
LF 401 & alkyl EO-PO ${ }^{2}$ block copolymer & 1200 & 4.17 \\
At 25 & alkyl EO polymer & 1350 & 3.70 \\
\hline
\end{tabular}

${ }^{1} \mathrm{EO}=$ ethylene oxide.

${ }^{2} \mathrm{PO}=$ propylene oxide.

HPLC analyses were performed with an HP 1050 pump, an HP1050 ALS autosampler, Shimadzu ELSD detector $\left(42^{\circ} \mathrm{C}, 250 \mathrm{kPa}\right.$ air pressure), and quantified using either an HP 3396A integrator or HP Chemstation for LC 3D (Agilent Technologies 1990-2002). The columns and conditions used were: ON 30 and ON 80 a Phenomenex Luna column ( $3 \mu \mathrm{m} \mathrm{C18}$ reversed phase, $150 \mathrm{~mm} \times 4.6 \mathrm{~mm}$ with a C18 guard column) and eluting solvent water:methanol:acetonitrile 10:70:20 v/v at $0.75 \mathrm{ml} / \mathrm{min}$. The At 11 , At 25 and LF 401 surfactants were analysed using a Brownlee Pecosphere column ( $3 \mu \mathrm{m}, 33 \mathrm{~mm} \mathrm{x}$ $4.6 \mathrm{~mm}$ with a $\mathrm{C} 18$ guard column) and solvent gradients appropriate for each compound using mixtures of $50 \%$ methanol, $100 \%$ methanol and $100 \%$ acetonitrile at $1 \mathrm{ml} / \mathrm{min}$ for varying periods. Each wash solution had $20 \mu \mathrm{g}$ (in $100 \mu \mathrm{l}$ ) of an internal standard (Agral 90, a nonylphenol ethoxylate; ICI, England) added and the total wash volume was made up to $10 \mathrm{ml}$ with $50 \%$ methanol. Standard solutions of each surfactant were made by adding up to 16 droplets of the formulation solution into a graduated test tube, adding $20 \mu \mathrm{g}$ of the internal standard, and making up the volume to $10 \mathrm{ml}$ as before. These were used to create the relative response curves for each surfactant and the recovered amounts in the leaf washes were calculated from these. Percentage uptake was calculated as the proportion of applied surfactant not recovered in the washes.

Droplet spread area was measured under UV illumination using V++ for Windows image analysis software (mean of 20 determinations). To visualise droplet spread, Blankophor-P fluor ( $5 \mathrm{~g} /$ litre; Bayer NZ) was incorporated into the treatments.

The statistical software package Statistix was used to analyse the data, with least significant difference (LSD) tests used to compare treatments. Stabilising transformations were performed, where required, prior to analysis.

\section{RESULTS AND DISCUSSION}

A comparison of the percentage uptake of each surfactant into fathen and wheat showed large differences $(\mathrm{P}=0.05)$ in uptake between species as well as between the surfactants (Fig. 1). Differences between surfactants are assumed to be due to structure. However, this representation of the results provides little insight into the mechanisms of uptake.

The droplet spread area varied between surfactant formulations (Table 2). This, together with the different molar concentrations (Table 1), can lead to quite different initial dosages, and it would be expected from previous work (Forster et al. 2004a) that the surfactants with greatest initial dose would show greatest uptake per unit area. In the case of fathen, when the mass uptake per unit area vs initial dose was plotted (Fig. 2), the results showed the expected increase with dose, with the higher initial dosage surfactants still close to the maximum uptake line $\left(\mathrm{R}^{2}=0.97\right)$. In the case of wheat, this relationship was not as strong $\left(\mathrm{R}^{2}=0.81\right)$, with considerable divergence from the maximum uptake line at the highest initial dosages. This indicates that other factors are involved, and are reducing the influence of the driving force, which is determined by initial dose.

This effect is most likely due to species differences (cuticular differences) where it has been observed previously that in contrast to lower molecular weight adjuvants, some species discriminate more against adjuvants of highest molecular weight (W.A. Forster, unpubl. data). 


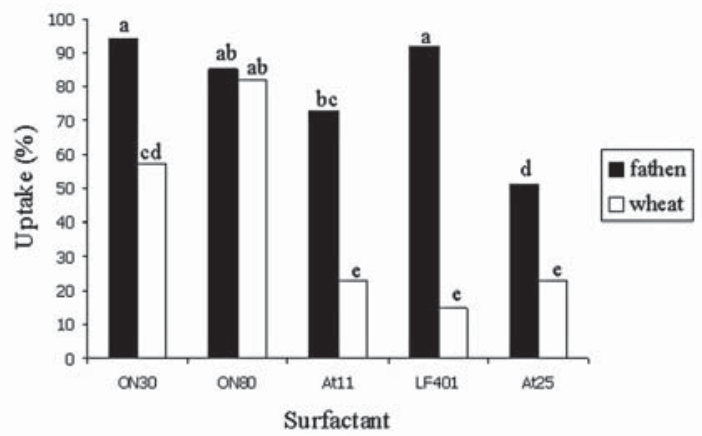

FIGURE 1: Uptake (\%) at $24 \mathrm{~h}$ of surfactants into fathen and wheat foliage. Treatments with no letter in common are significantly different $(\mathbf{P}=\mathbf{0 . 0 5})$.

TABLE 2: Surfactant spread area and initial dose when applied to fathen and wheat.

\begin{tabular}{lcccccc}
\hline & \multicolumn{2}{c}{ Spread Areas $\left(\mathrm{mm}^{2}\right)^{1}$} & & \multicolumn{2}{c}{ Initial Dose $\left(\mathrm{nmol} / \mathrm{mm}^{2}\right)$} \\
\cline { 2 - 3 } \cline { 5 - 6 } Surfactant & Fathen & Wheat & & Fathen & Wheat \\
\hline ON 30 & $55.49 \mathrm{a}$ & $51.88 \mathrm{a}$ & & 0.07 & 0.08 \\
ON 80 & $2.90 \mathrm{~b}$ & $2.85 \mathrm{~b}$ & & 0.81 & 0.83 \\
At 11 & $0.74 \mathrm{c}$ & $0.48 \mathrm{~d}$ & & 2.20 & 3.40 \\
LF 401 & $0.71 \mathrm{c}$ & $0.41 \mathrm{e}$ & & 1.49 & 2.45 \\
AT 25 & $0.45 \mathrm{de}$ & $0.37 \mathrm{f}$ & & 1.97 &
\end{tabular}

${ }^{1}$ Treatments with no letter in common are significantly different $(\mathrm{P}=0.05)$.

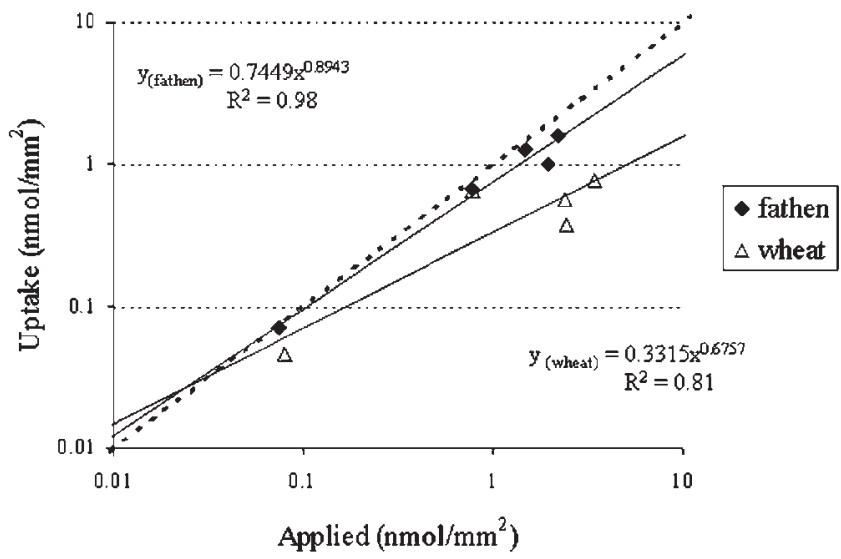

FIGURE 2: Uptake at $24 \mathrm{~h}$ of surfactants into fathen and wheat foliage plotted against the initial dose applied. The dotted line indicates the maximum uptake, representing $100 \%$ uptake over the initial dose range.

Furthermore, when percentage concentration is maintained, an increase in molecular weight will decrease the nmol per unit area as well as the total mass (nmol) applied, and therefore total nmol uptake will be lowered (as per 100\% uptake line in Figure 3). This 
effect is observed in both fathen and wheat species together with the previously noted species difference effect. Although the current study used only a limited number and range of surfactants, this relationship has held true for a much wider number and range of surfactants, across different plant species (W.A. Forster, unpubl. data).

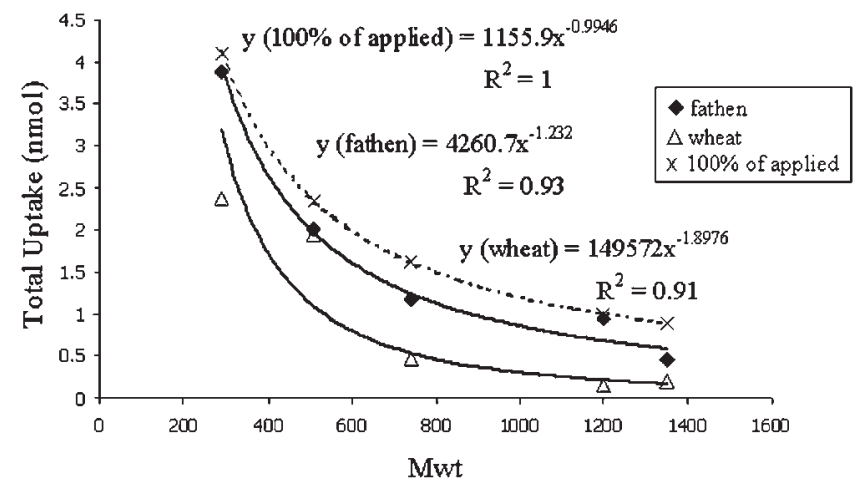
FIGURE 3: Uptake (nmol) at $24 \mathrm{~h}$ of surfactants into fathen and wheat foliage plotted against molecular weight. The dotted curve represents $100 \%$ uptake.

It has been proposed that there is a requirement for surfactants to be absorbed into plant leaves at rates similar to those for the active ingredient for best uptake results (Stevens \& Bukovac 1987; Stock et al. 1993). However, there have been only a few studies of surfactant uptake (Stevens \& Bukovac 1987; Stock et al. 1992; Zabkiewicz et al. 1995) compared to the multitude of studies quantifying active ingredient uptake, and all of these are reported on a percentage basis. The recent finding (Forster et al. 2004a) that active ingredient mass uptake can be related to initial dose applied, immediately raises the question of whether the surfactant component of a typical spray formulation will behave in a similar fashion. The current work is a first step towards addressing that question.

Plotting the mass uptake per unit area $\left(\mathrm{nmol} / \mathrm{mm}^{2}\right)$ shows that there is a good relationship with initial dose applied (Fig. 2). This trend has also been observed with the active ingredient and related model compounds in previous studies (Zabkiewicz \& Forster 2003; Forster et al. 2004a,b). It can be seen that there are differences between the two species tested, with less uptake into wheat particularly at higher initial doses. This is contrary to expectations from the initial dose data where wheat had higher initial doses than fathen for all surfactants (Table 2).

\section{CONCLUSIONS}

It is clear that there is a considerable species difference, with less uptake by wheat, and when surfactant percent concentration is held constant, then uptake decreases as molecular weight increases. Although this study does not consider the rates of surfactant uptake, it does demonstrate clearly that within a certain molecular weight range, surfactant uptake (as measured in molar amounts) does follow the same trends and relationships as found for pesticide active ingredients, with the proviso that molecular weight or structure may modify the absolute values.

It is proposed that a combination of surfactant initial dose and molecular weight will give a better prediction of surfactant uptake than initial dose alone. Other surfactant structural parameters will also have an effect, but molecular weight is a dominant factor within surfactants that are known to penetrate well. 


\section{ACKNOWLEDGEMENTS}

Thanks are due to BASF, who provided the chemicals and partial funding for this work, and Robyn Gaskin for reviewing the manuscript.

\section{REFERENCES}

Forster WA, Zabkiewicz JA, Reiderer M 2004a. Mechanisms of cuticular uptake of xenobiotics into living plants: 1. Influence of xenobiotic dose on the uptake of three model compounds, applied in the absence and presence of surfactants into Chenopodium album, Hedera helix and Stephanotis floribunda leaves. Pest Management Science 60: 1105-1113.

Forster WA, Zabkiewicz JA, Reiderer M 2004b. Mechanisms of cuticular uptake into living plants: Influence of xenobiotic dose and surfactant on uptake. Proceedings of the 7th International Symposium on Adjuvants for Agrochemicals. Pp. 83-91.

Stevens PJG, Bukovac MJ 1987. Studies on octylphenoxy surfactants. Part 2: Effects on foliar uptake and translocation. Pesticide Science 20: 37-52.

Stock D, Holloway PJ 1993. Possible mechanisms for surfactant-induced foliar uptake of agrochemicals. Pesticide Science 38: 165-177.

Stock D, Edgerton BM, Gaskin RE, Holloway PJ 1992. Surfactant-enhanced foliar uptake of some organic compounds: Interactions with two model polyoxyethylene aliphatic alcohols. Pesticide Science 34: 233-242.

Stock D, Holloway PJ, Grayson BT, Whitehouse P 1993. Development of a predictive uptake model to rationalise selection of polyoxythylene surfactant adjuvants for foliage-applied agrochemicals. Pesticide Science 37: 233-245.

Zabkiewicz JA, Forster WA, Steele KD, Liu, ZQ 1995. Comparison of uptake into field bean (Vicia faba) of organosilicone and non-silicone surfactants. Fourth International Symposium on Adjuvants for Agrochemicals. Pp. 219-224.

Zabkiewicz JA, Forster WA 2003. Development of simple models for agrichemical uptake into plant foliage. New Zealand Plant Protection 56: 61-65. 